\title{
Transgresiones discursivas y cultura de la seguridad: los pánicos político-morales en la esfera pública española
}

\author{
Juan Pecourt \\ Universitat de València \\ juan.pecourt@uv.es \\ Jorge Resina \\ Universidad Complutense de Madrid \\ jresina@ucm.es
}

Recepción: 14-11-2019

Aceptación: 16-04-2020

Publicación: 15-10-2020

\section{Resumen}

En los últimos años se han producido diversas controversias en la esfera pública española a partir de mensajes humorísticos o críticos que cuestionaban la sacralidad de determinados símbolos identitarios y nacionales. Entre otros, pueden citarse las polémicas generadas por el escritor Guillermo Zapata, la tuitera Cassandra Vera y el rapero Valtònyc. Siguiendo el marco analítico de los pánicos morales elaborado por Stanley Cohen en los años setenta, y actualizado posteriormente, analizamos la construcción mediática de estos «demonios populares», así como el posicionamiento de los diferentes actores implicados. Para ello, identificamos tres momentos en la construcción de estos pánicos: cultivo, operación y disipación. Y observamos su mutación a lo largo del tiempo, desde un comienzo donde es difícil diferenciar entre pánico moral y escándalo político hasta una etapa de madurez en la que pueden distinguirse claramente ambos fenómenos. Nuestro planteamiento es que estos pánicos morales son un elemento distintivo dentro de las controversias políticas generadas en la esfera pública, que reflejan además una cultura de la seguridad específica en España, sobre todo tras la aprobación de la Ley de Seguridad Ciudadana y la reforma del Código Penal en 2015.

Palabras clave: pánico moral; esfera pública; cultura de la seguridad; escándalo político 
Abstract. Discursive transgressions and security culture: Political-moral panics in the Spanish public sphere

In recent years, various controversies have arisen in the Spanish public sphere stemming from humorous or critical messages that questioned the sacredness of certain identity and national symbols. Among others, the controversies sparked by the writer Guillermo Zapata, the tweeter Cassandra Vera and the rapper Valtònyc are notable. Following the analytical framework of moral panics developed by Stanley Cohen in the 1970s, and later updated, we analyze the media construction of these "popular demons," as well as the positioning of the different actors involved. To this end, we identify three moments in the construction of these panics: cultivation, operation and dissipation. We observe their mutation over time, from a beginning where it is difficult to differentiate between moral panic and political scandal to a stage of maturity in which both phenomena can be clearly distinguished. Our approach is that these moral panics are a distinctive element within the political controversies arising in the public sphere, which also reflect a specific security culture in Spain, especially after the passage of the Citizen Security Law and the reform of the Code Criminal in 2015.

Keywords: moral panic; public sphere; security culture; political scandal

\section{Sumario}

Introducción 3. Conclusiones

1. Discusión conceptual Agradecimiento y financiación

2. La aparición de pánicos político- Referencias bibliográficas morales en la esfera pública española

\section{Introducción}

Durante los últimos años se han sucedido en España varios eventos polémicos que han tenido como protagonistas a músicos, tuiteros y humoristas que abordaron de forma irónica o satírica temas de consenso nacional, como el terrorismo, la corona o los símbolos patrios. Estas referencias tuvieron una repercusión social y jurídica que terminó con los autores en los tribunales, acusados de la comisión de delitos como enaltecimiento del terrorismo, humillación a las víctimas o incitación al odio.

Este artículo presenta algunos de estos casos y los aborda desde el ámbito de la esfera pública, para analizar cómo eventos que en un momento parecen irrelevantes, en otros adquieren gran visibilidad y se convierten en amenaza para el orden social, con repercusiones penales. Como mecanismo explicativo, partimos de la teoría de los pánicos morales formulada décadas atrás por Stanley Cohen (1972) y la actualizamos hasta nuestros días.

El objetivo del artículo es doble: por un lado, reflexionar teóricamente sobre la creación de pánicos morales, específicamente políticos, como instrumento habitual del ámbito político-mediático; por el otro, analizar la aparición de episodios concretos en España tomando como referencia temporal la entrada 
en vigor del nuevo marco legal derivado de la aprobación de la Ley Orgánica de Protección de la Seguridad Ciudadana (LOPSC) y la reforma del Código Penal en 2015.

El artículo se estructura como sigue. Primero se debate sobre la noción de pánico moral y sus derivaciones actuales. Se relaciona el concepto con el de escándalo político y se plantea la emergencia de un subtipo específico de pánico moral (el pánico político-moral), que sintetiza rasgos de ambos conceptos adaptados al escenario contemporáneo. Después se presentan los tres casos de estudio, el criterio de selección y las fases de las que consta el análisis.

Segundo, se analizan los casos seleccionados para el contexto español: el del concejal de Madrid Guillermo Zapata, el de la tuitera Cassandra Vera y el del rapero Valtònyc. Se parte de una primera etapa común de cultivación de estos pánicos que coincide con el ciclo de movilizaciones abierto con el $15 \mathrm{M}$ y que tiene como respuesta institucional un nuevo marco legal (Calle Collado, 2016). Posteriormente, se aborda cada uno de los casos y se estudian los rasgos específicos en su fase de operación y los efectos que dejan cuando se disipan.

Por último, las conclusiones plantean el surgimiento de varias tipologías de pánicos político-morales, con el modelo híbrido de Zapata y los casos puros de Cassandra y Valtònyc. Se sistematizan los rasgos comunes y se presenta el recorrido que ha tenido el concepto. El artículo termina con una discusión sobre el surgimiento de nuevos casos y sus ramificaciones.

\section{Discusión conceptual}

\subsection{El concepto original de pánico moral}

Desde los años setenta, el concepto de pánico moral se utiliza en el ámbito académico anglosajón para definir determinados tipos de riesgos sociales y también ciertas formas de control social. El concepto original lo desarrolló Cohen en su libro Folk devils and moral panics (1972) y lo define como «una condición, episodio, persona o grupo, que se define como una amenaza para los intereses y los valores de la sociedad; su naturaleza se presenta de forma estilizada y estereotipada por los mass media; se construyen barricadas morales por parte de editores, arzobispos, políticos y otras personas de pensamiento conservador» (Cohen, 2011 [1972]: 9).

El objetivo era estudiar la presentación de los medios y las reacciones públicas de los conflictos producidos entre las subculturas mod y rocker en la Inglaterra de los años sesenta. Cohen identificó cinco colectivos que participaron en el proceso de construcción social del pánico moral: a) los agentes de control; $b$ ) los mass media; $c$ ) el público; $d$ ) los legisladores y políticos; y e) los grupos de interés (por ejemplo, los denominados moral entrepeneurs). Enfatizaba la centralidad de los mass media en la construcción de los pánicos morales y, por ello, en la definición de las amenazas sociales existentes y las nuevas formas de control social. Ya no se trata de fenómenos episódicos e irrelevantes, sino que tienen implicaciones políticas más amplias (Fernández de Mosteyrín, 2018: 2-3). 
Años más tarde Stuart Hall y sus colegas expandieron la concepción del pánico moral de Cohen en su libro Policing the Crisis: Mugging, the State, and Law and Order (1978), con la introducción de la noción gramsciana de la ideología. Definen el pánico moral como «una de las formas principales que adopta la conciencia ideológica, mediante la cual se gana el apoyo de la "minoría silenciosa" para adoptar medidas cada vez más coercitivas por parte del Estado, proporcionando legitimidad a formas excepcionales de ejercer el control» (Hall, 1978: 221).

Estos autores sitúan el pánico moral dentro del proceso de construcción de una nueva hegemonía política y consenso social, y se centran en el papel que tienen los medios (como "definidores secundarios») en la reproducción de los marcos de referencia que los poderosos realizan de la vida social. Estudiaron el pánico moral surgido en la Inglaterra de los años setenta en torno a la criminalidad de baja intensidad realizada por clases obreras y colectivos de inmigrantes. Las constantes portadas mediáticas y las acciones represivas de diferentes actores sociales funcionaron como una estrategia discursiva para romper la hegemonía política de posguerra, centrada en torno a la sociedad del consumo y el estado de bienestar. Se impulsó un nuevo consenso social autoritario, relacionado con las fuerzas de la «ley y orden» y el naciente Estado neoliberal. Esta redefinición del consenso social incluía en su seno el desmantelamiento progresivo del estado de bienestar y la puesta en cuestión de la permisividad social que caracterizó los años sesenta, influidos por los movimientos contraculturales.

\subsection{La evolución de los pánicos morales}

La concepción inicial de pánico moral ha tenido muchas revisiones posteriores, debido a las profundas transformaciones que se han producido en las sociedades occidentales desde los años setenta. En general, para que el concepto de pánico moral tenga utilidad, debe diferenciarse claramente de otros conceptos similares y su operacionalización ha de ser factible. No todos los problemas sociales ni todas las noticias escandalosas son pánicos morales. Algunos críticos aseguran que el concepto se ha ampliado tanto, se ha utilizado en contextos tan diversos, que ha perdido su significado original y también la relevancia que tuvo en su inicio (Jewkes, 2015; Ungar, 2001). Es necesario tener en cuenta las diferencias entre pánico moral y otros tipos de preocupaciones públicas. En otras palabras, los pánicos morales deberían verse como un fenómeno específico dentro de un conjunto más amplio de fenómenos que incluyen la regulación moral, las preocupaciones sociales y los discursos ideológicos.

Tradicionalmente, el estudio de los pánicos morales se ha realizado sobre todo en el ámbito de la sociología de la desviación. Suelen entenderse como un proceso de estigmatización hacia un determinado colectivo, alejado de la norma establecida por la sociedad convencional y, por tanto, definido como inmoral y socialmente peligroso (entre los colectivos estudiados se encuentran las subculturas juveniles, los adictos a las drogas, las sectas satánicas y los pedófilos). 
Klocke y Muschert (2010) añaden que estos colectivos desviados tienden a representarse a través de los medios de forma estereotipada (se construyen como demonios populares o folk devils). Se diferencian de otros episodios en los que participan personas individuales (por ejemplo, el affaire Lewinsky de Bill Clinton), o de riesgos sociales más generales y abstractos (por ejemplo, el cambio climático). Los autores tratan de diferenciar los pánicos morales de los escándalos políticos, aunque sin entrar en la significación concreta de este tipo de escándalos.

Adoptamos las críticas de la noción tradicional de pánico moral, especialmente las aportaciones de McRobbie y Thornton (1995) y Garland (2008) cuando observan que en el complejo panorama mediático actual se ha convertido en una forma de actuación específica dentro de la esfera pública, que muchas veces escapa al control de los poderes establecidos. Garland incluso diferencia entre "pánicos morales comerciales» y "pánicos morales políticos», e incide en la normalidad de este tipo de fenómenos en la esfera pública contemporánea. Mientras que los primeros consisten en simples estrategias comerciales para lanzar al mercado determinados productos de consumo (la expansión de la tendencia acid house en los noventa del siglo xx), que tienen una presentación provocadora pero que son políticamente inocuos, los segundos tienen una intencionalidad política más evidente y efectos políticos visibles (la quema del Reichstag en los años treinta del siglo xx). De todas formas, en su estudio, Garland no indaga en la diferencia entre estos dos tipos de pánicos morales.

\subsection{Escándalo político y el pánico moral}

Nuestra tesis es que en el espacio de la discusión pública se está normalizando un fenómeno específico que tiene rasgos comunes a lo que tradicionalmente entendemos por escándalo político, o de poder, y que comparte la lógica de los pánicos morales de los "grupos desviados»: una tipología particular de pánicos político-morales. Este proceso forma parte de la mediatización creciente del campo político y de la esfera pública, impulsada en distintas oleadas por la prensa de masas, la televisión y, más recientemente, internet (Thompson, 1995).

Tanto Markovits y Silverstein (1988) como Thompson (2000) sitúan los escándalos políticos en un contexto social interseccional entre lo político y lo mediático. El escándalo se produce cuando el campo mediático expone una actuación que resulta ilegítima desde el punto de vista del comportamiento público, aunque sea habitual dentro de las lógicas competitivas establecidas en los núcleos del poder político, inaccesibles a la opinión pública. Se trata de fugas de información desde el ámbito de la política restringida hacia el ámbito de la opinión pública. Según Thompson (2000), los escándalos políticos son un elemento central de la lucha política actual, y pueden dilapidar el capital simbólico (reputación y reconocimiento) del individuo afectado, un recurso esencial para tener éxito en el campo político.

$\mathrm{Al}$ igual que el escándalo político, los pánicos político-morales se orquestan en el espacio público y, aunque generen revuelo mediático e inevitablemente 
tengan efectos políticos, no siguen la misma lógica. La diferencia básica entre ambos es que los escándalos políticos surgen de la arena política (de su campo más restringido) (Thompson, 2000), son filtraciones en la arena pública de comportamientos originariamente pensados en espacios no abiertos al público. Sin embargo, los pánicos político-morales son construidos por los mass media para el público, no surgen directamente del campo político (aunque este pueda tener algún papel en su difusión). La intención inicial es la publicidad, no el ocultamiento, aunque los creadores puedan perder después el control de su difusión.

Por otro lado, la construcción por parte de los mass media (y las redes sociales) de estos pánicos político-morales sigue la misma lógica que la de los pánicos morales «clásicos» identificados por Cohen. Entre otros: $a$ ) identificación de un comportamiento que se considera una amenaza para la sociedad; b) dramatización de los medios de dicho comportamiento; c) aparición de la indignación pública; $d$ ) puesta en escena de políticos y otras autoridades que exigen una disculpa y apartar al sujeto afectado de la visibilidad mediática; $e$ ) petición de cambios legislativos para evitar esos comportamientos; $f$ ) rápida disolución de la controversia pública.

Sin embargo, los pánicos político-morales tienen tres características que los diferencian de los pánicos morales clásicos: $a$ ) no se centran en colectivos sociales "desviados», sino en personalidades específicas que tienen gran relevancia mediática (artistas, cantantes o presentadores de televisión); $b$ ) no se relacionan tanto con las conductas desviadas como con la utilización transgresora de símbolos identitarios, nacionales y políticos (bandera, himno, monarquía, etcétera); y c) no se centran en los "pequeños malvados» (small villains) (Jenkins, 2009), sino en figuras socialmente prominentes, los «malvados mediáticos».

La proliferación de los pánicos político-morales, sin ser extensivos a toda la sociedad, muestra la forma que adoptan los conflictos culturales (culture wars) contemporáneos y los choques entre distintos sistemas normativos (Picó y Pecourt, 2013). Sin duda, pueden entenderse como mecanismos de control impulsados por ciertos colectivos para imponer cambios sociales, pero dada la fragmentación de la sociedad y el panorama mediático actual, no alcanzan el nivel de generalidad que asumieron Cohen y Hall en sus trabajos. Lo que para ciertos colectivos es un "malvado mediático», para otros puede ser un "héroe mediático".

Esa fragmentación a la que aluden McRobbie y Thornton (1995) se ha incrementado aún más con la implantación de la cultura digital (Lindgren, 2013). La complejidad de los medios implica que muchas veces los demonios populares son apoyados por los mismos medios que los construyen como enemigos públicos. De manera cada vez más intensa, el desarrollo de los medios sociales (desde los blogs hasta Twitter) permite que las personas definidas por sus conductas «desviadas" puedan defenderse desde «sus propios nichos y micromedia» (McRobbie y Thornton, 1995: 559). En el caso que nos ocupa, veremos que Twitter tiene un papel fundamental en este sentido: impulsa reacciones de repulsa y condena contra los demonios populares, pero al mismo 
tiempo permite la construcción de plataformas de apoyo y defensa. Este es el caso de los tags que surgen para demonizar o defender a los distintos sujetos implicados, y que impulsan diversas formas de activismo digital (Resina, 2010; Pecourt, 2015).

\subsection{El estudio de los pánicos político-morales: cultivo, operación y disolución}

Para el estudio de los pánicos morales políticos en la esfera pública, seguimos un esquema de análisis en el que a) es resultado de la interacción entre distintos actores y de la discusión que se genera entre ellos, y b) sigue la secuencia descrita por Klocke y Muscher (2010): son más probables en contextos críticos, aparecen como episodios y acaban disipándose al cabo de unos días o semanas.

Sobre el primer aspecto, debido al proceso de apertura de la esfera pública, la construcción de un pánico moral no puede entenderse solo desde una perspectiva elitista (top-down), ya que también se generan muchos discursos desde abajo $($ bottom-up). El resultado es un complejo juego de interacciones sociales entre distintos actores: emprendedores morales, políticos, medios, activistas y público en general, con una pluralidad de prácticas discursivas, valores y creación de identidades que sirve de reposicionamiento ideológico.

Sobre el segundo aspecto, el modelo de Klocke y Muscher (2010) diferencia tres fases:

1. El cultivo. Se refiere a las condiciones iniciales que hacen posible el surgimiento del pánico moral. Es el periodo previo, marcado por lo general por un conflicto entre universos morales. En ese sentido, situaciones de crisis económica y política, así como momentos de cambio social y de valores, hacen más probable la aparición de los pánicos.

2. La operación. Es la etapa en la que aparece como tal el episodio que produce el pánico moral, en que se presenta como problema. En esta fase se identifican los demonios populares, los hechos se magnifican; tienen lugar reacciones de los distintos actores (promotores morales, fuentes oficiales, líderes de opinión, masa crítica) y se termina solicitando acciones que regulen el comportamiento de quienes provocaron el pánico moral.

3. La disolución. Es el periodo final, cuando el pánico pierde relevancia en la esfera pública, o bien porque se normalizó, o bien porque se produjo una transformación (una reforma legal, por ejemplo), o bien simplemente porque se disipó al perder interés o al ser sustituido por otro evento.

Estos episodios, aunque emergen y se disipan de forma súbita, reflejan el conflicto entre diferentes sistemas de valores y, por ello, tienen impacto en la cultura cívica (Hall, 1978). Trasladan la lógica de la rivalidad política al ámbito de la sociedad civil. Pueden establecerse paralelismos con los conflictos del campo político, pero al mismo tiempo tienen características diferenciales respecto a este, al desarrollarse con cierta autonomía propiciada por las dinámicas propias de los medios de comunicación (Chavero, 2015). 


\subsection{Los pánicos político-morales en España: los casos de Zapata, Cassandra $y$ Valtònyc}

Nuestro interés es estudiar una serie de pánicos político-morales que han surgido en la esfera pública española tras la aprobación de la LOPSC y la reforma del Código Penal en 2015. Se trata de un momento especialmente interesante porque el cambio legislativo se aprueba cuatro años después de la aparición del $15 \mathrm{M}$ y el inicio de un nuevo ciclo de movilizaciones en España que cuestiona algunos de los consensos básicos de la transición (periodo de cultivo).

Desde entonces, se han producido varios casos que encajarían en la caracterización previa. Esto es: personas socialmente prominentes que han hecho un uso transgresor de símbolos políticos y nacionales y que, de pronto, pasan a ocupar durante varias semanas el primer plano de la esfera pública convertidos en «malvados mediáticos». Estos episodios tienen un fuerte impacto en un breve periodo de tiempo (periodo de operación), y desaparecen posteriormente en la agenda informativa mientras el interés se desplaza a otros temas (periodo de disolución).

En las próximas páginas, se analizan tres casos representativos de la aparición de pánicos morales políticos en la esfera pública española. Todos tienen elementos comunes (comparten las características y la periodización propia de los pánicos morales), pero también elementos diferenciales que muestran cierta mutación.

En primer lugar, se analiza el caso de Guillermo Zapata, que consideramos pionero dentro del contexto sociopolítico generado por la LOPSC. Se trata todavía de un caso «híbrido» entre escándalo político y pánico moral: el momento inaugural del pánico moral post-15M. Tiene elementos de escándalo político porque se inscribe dentro de las batallas reputacionales existentes en el campo político, pero también empieza a adquirir elementos diferenciales que lo aproximan al pánico moral, por el protagonismo de los medios en la construcción del caso y su manera de presentar al villano mediático.

En segundo lugar, se estudia el caso de Cassandra Vera, que constituye un pánico moral político en el sentido "puro" del término. Se construye en los medios de comunicación (su origen se encuentra en las redes sociales) y mantiene la lógica específica de los medios. Se trata de una persona anónima, ajena al campo político, que emite una serie de opiniones en el entorno digital que provocan la reacción coordinada de instancias policiales, mediáticas y jurídicas, así como el realineamiento ideológico de los partidos políticos, que condenan o defienden a la autora.

Finalmente, se examina el caso de Valtònyc que constituye otro ejemplo "puro», pero que se asocia no solamente al principio participativo de la esfera pública digital, como en el caso de Cassandra, sino también a la dinámica expresiva y creativa de la cultura popular (en este caso, el rap). El caso de Valtònyc anuncia la politización progresiva de esta cultura popular (cantantes, humoristas, presentadores de televisión), y su inserción dentro de la lógica de los pánicos morales. 
Para estudiar la evolución de estos pánicos en la esfera pública, partimos del análisis de la opinión publicada en la prensa de referencia y reproducimos narrativamente el debate de las opiniones más significativas centrándonos en cómo se representaron los «demonios populares», qué discursos y contradiscursos se generaron, qué alineamientos se dieron y quiénes fueron los principales emprendedores morales (Wright, 2015).

Esta elección se justifica por el prestigio y la influencia que la prensa sigue teniendo para conformar la opinión pública, especialmente en el ámbito del comentario político. Puede realizarse una distinción entre el espacio restringido de las élites comunicativas, ocupado fundamentalmente por profesionales del periodismo, y el espacio masificado de los participantes desconocidos, y por ello menos relevantes. En ese sentido, los actores del espacio restringido siguen teniendo una influencia fundamental en la construcción y la legitimación social de los «demonios populares» en la esfera pública (Jacobs y Townsley, 2011). ${ }^{1}$

Para la selección de medios nos hemos basado en los periódicos de mayor difusión en España, según criterios de diversidad ideológica. Este rasgo es especialmente importante para el caso español, al contar con un sistema mediático de pluralismo polarizado (Hallin y Mancini, 2011). Es decir, la prensa tiene una fuerte relación con la política partidista y se organiza en torno a la división ideológica de partidos. La selección de medios responde así a la oposición existente en el campo periodístico español entre prensa "conservadora" y prensa «progresista». Con ello, observamos los posicionamientos de estos medios y su papel en la construcción de los diferentes «demonios populares». Mientras que unos participan activamente en su construcción, otros tienden a resistir estos procesos de demonización social.

De esta forma, en el ámbito conservador hemos rastreado la hemeroteca digital de los diarios $A B C$, La Razón, Ok Diario y Libertad Digital; en el centro, de más liberal a más progresista, El Mundo, El Confidencial y El País; y en el ámbito progresista, eldiario.es y Público. Además, para el caso de Valtònyc, revisamos los dos principales diarios catalanes, La Vanguardia y El Periódico. El estudio se complementa con el análisis de tags específicos para cada caso en Twitter, identificando qué posicionamientos polarizados (pro y contra) se dan similares a la prensa de referencia. ${ }^{2}$

Para acotar la duración del análisis de cada uno de los casos, hemos rastreado cuál es el periodo en el que aumenta el número de búsquedas de los tres «demonios populares» en internet con la herramienta Google Trends, que refle-

1. En ese sentido, esta investigación parte del estudio de las representaciones sociales que hacen los comentaristas políticos, en calidad de emprendedores morales y líderes de opinión, a través de sus columnas en periódicos y en cómo esas opiniones influyen en el debate que se genera en la esfera pública.

2. Este análisis se incluye con el fin de contextualizar la discusión en el conjunto de la esfera pública y establecer algunas relaciones, ya sea de forma sucinta, entre la opinión publicada en los periódicos y su impacto en las redes sociales, en este caso, Twitter. 
ja el interés de búsqueda de un término en Google. ${ }^{3}$ De esta forma, dentro del año en el que sucede el episodio, tomamos como referencia el lapso de máxima popularidad, en el que se registran las mayores frecuencias de búsqueda, como indicativo del tiempo en el que se desarrolló el pánico político-moral. ${ }^{4}$

\section{La aparición de pánicos político-morales en la esfera pública española}

\subsection{El cultivo del pánico: el 15M y la Ley de Seguridad Ciudadana}

La fase de cultivo común a los tres pánicos político-morales se produce entre los años 2011 a 2015. España vive las consecuencias más dramáticas de la crisis económica y se inicia un nuevo ciclo de protesta que comienza con el 15M. La respuesta a estas movilizaciones se canaliza desde el ámbito jurídico-político con la aprobación de un nuevo marco legal orientado a regular el espacio y la esfera pública que tiene como argumento reforzar la seguridad ciudadana. El resultado es un contexto conflictivo que pone las bases para el surgimiento de una nueva tipología de pánicos específicamente políticos, como espacios discursivos de disputa ideológica entre distintos universos políticos y simbólicos que se libra en medios y redes.

El 15M supuso un punto de inflexión al quebrar el imaginario de consenso en torno a la "cultura de la transición", que durante décadas había servido como principal elemento de cohesión nacional (Fernández-Savater, 2012; Martínez, 2012; Morán, 2011). Por un lado, adquiere protagonismo una nueva generación política que cuestiona estos acuerdos, a los que percibe lejanos, y, por el otro, se filtran escándalos de corrupción que involucran a reconocidos partidos y líderes. Ello provoca una deslegitimación generalizada de la élite política tradicional, a la que se considera heredera de la transición y se responsabiliza de la crisis (Toret, 2013; Castromil y Resina, 2013).

Además, los movilizados encuentran nuevos canales de expresión y activismo a través de las tecnologías y redes digitales (Resina, 2011; Castells, 2012). Es en estos espacios donde se desarrollan formas novedosas de interacción y lenguajes propios, que se caracterizan sobre todo por el uso del humor y la ironía para «desacralizar» el relato de la transición (Romanos, 2017; Labrador, 2014). Con ello, se profundiza en la ruptura de ciertos temas tabú, como la monarquía, y se ponen en marcha nuevos proyectos satíricos como Mongolia o El Mundo Today, que se suman a publicaciones clásicas como El Jueves.

Estos espacios de apertura contrastan con el resultado de las elecciones generales de noviembre de 2011, en las que se produce la victoria por mayoría

3. Trends sirve para medir el interés de un tema a lo largo del tiempo, a través de frecuencias relativas de búsqueda en Google, de forma que el mayor valor corresponde a 100, momento de máxima popularidad de un término, y 0 es el menor valor, correspondiente a falta de datos por ausencia de búsquedas.

4. Para el caso de Guillermo Zapata, el periodo abarca del 7 al 27 de junio de 2015; para Cassandra Vera, del 19 de marzo al 15 de abril de 2017; y para Valtònyc, del 11 de febrero al 10 de marzo, y del 6 de mayo al 16 de junio de 2018. 
absoluta del Partido Popular. A las movilizaciones de los indignados, las sucede una reacción conservadora que demanda regular estas nuevas formas de expresión con el fin de restablecer el orden público.

La discusión no tarda en ingresar en el Congreso de los Diputados con el argumento de reforzar la seguridad ciudadana ante «los problemas de la multirreincidencia y la violencia callejera». ${ }^{5}$ El siguiente paso se produce a finales de 2013, cuando el Gobierno presenta el proyecto de ley para regular «la aparición de nuevas manifestaciones de conductas antisociales» en la calle y en las redes sociales. ${ }^{6}$

El debate parlamentario refuerza dos posturas contrapuestas en torno al eje seguridad (mayoría conservadora) / libertad (oposición progresista). Una disputa que se extiende a los medios de comunicación, que replican la división de acuerdo a la proximidad / lejanía ideológica con el Gobierno, de forma que cuanto más a la derecha, los medios encuadran el debate legislativo en términos securitarios, y cuanto más a la izquierda, en términos de libertad de expresión (Durán, 2018).

A pesar de la discusión, la mayoría parlamentaria conservadora facilita la tramitación legislativa de la LOPSC, que se aprueba por mayoría absoluta en marzo de 2015 y entra en vigor el 1 de julio, junto a la reforma del Código Penal. El resultado es un nuevo marco legal que refuerza la actuación policial, incluye nuevos tipos penales y endurece las sanciones de delitos como el enaltecimiento del terrorismo, la humillación a las víctimas, las calumnias e injurias contra la corona, y las ofensas a símbolos nacionales. ${ }^{7}$

Este cambio legal afecta sobremanera al ámbito digital, ahora especialmente regulado, y provoca que diversas manifestaciones que hasta ese momento se habían considerado inocuas comiencen a ser delictivas, como sucede con

5. La primera moción fue presentada en 2012 por el Grupo Parlamentario Catalán (Convergència i Unió) y fue aprobada por el propio Grupo Parlamentario Catalán (Convergència i Unió) y el Grupo Parlamentario Popular (BOCG. Congreso de los Diputados, serie D, núm. 124, de 06/07/2012, pág. 16).

6. Dentro de los argumentos recogidos por el Gobierno para la presentación del proyecto de ley en el Congreso de los Diputados, se señala la necesidad de regular «la aparición de nuevas manifestaciones de conductas antisociales» en el ámbito de las nuevas tecnologías, ya que «demandan una respuesta adecuada». Proyecto de Ley Orgánica de Protección de la Seguridad Ciudadana. Ministerio del Interior. Gobierno de España. Disponible en línea en <https://www.lamoncloa.gob.es/serviciosdeprensa/notasprensa/documents/proyecto_ lopsc_11-07-14.pdf última visita: 2-07-2019>.

7. Con la aprobación de la LOPSC, se produjeron modificaciones del régimen sancionador (con sanciones administrativas de hasta 600.000 euros), se creó un registro de infracciones contra la seguridad ciudadana y se ampliaron las potestades policiales, con el límite del derecho de manifestación. En cuanto a la reforma del Código Penal, el punto más controvertido fue la introducción de la prisión permanente revisable y la sanción con penas de prisión de delitos de enaltecimiento del terrorismo, humillación a las víctimas (art. 578) y calumnias e injurias contra la corona (art. 490), junto a penas de multa por ofensas a símbolos nacionales (art. 543) o que puedan dañar el prestigio de la corona (art. 491). También se recoge la tipificación de dichos delitos cuando se hayan producido por internet (hasta ese momento considerado falta). 
nuestros tres casos de estudio. Tanto Zapata como Cassandra y Valtònyc son procesados por expresiones de humor negro y creaciones satíricas que antes habían pasado desapercibidas. El proceso de securitización de la esfera pública agudiza la tensión entre libertad de expresión y seguridad, lo que genera nuevos espacios de disputa discursiva que responden a una lucha entre bloques ideológicos y visiones de la sociedad, un terreno fértil para la creación de pánicos morales-políticos.

\subsection{El análisis de casos: Zapata, Cassandra y Valtònyc}

\subsubsection{Entre el «escándalo político» y el "pánico moral»: el caso de Guillermo Zapata}

El caso de Zapata es relevante porque es el primer pánico moral que se desata en los medios posiblemente debido a la LOPSC. Además, muestra el deslizamiento del escándalo político clásico (desvelamiento de información desde el campo político hacia la esfera pública) hacia la lógica del pánico político-moral (construcción de un demonio popular, reflejo de determinados males sociales que deben confrontarse) en la era de las redes sociales.

El debate emerge en un contexto dominado por la presencia constante de escándalos políticos en el sentido dado por Thompson (2000) (como el caso Gürtel en el ámbito español o la Operación Púnica en la Comunidad de Madrid), ya que surgen de informaciones filtradas desde el campo político «oculto» y que afectan la imagen del partido ante la opinión pública. Más concretamente, se trata de escándalos políticos asociados a fenómenos de corrupción política y económica.

El origen de la polémica se sitúa en los años 2011 y 2012, cuando Zapata escribió diversos tuits de humor negro en los que hacía referencia al Holocausto e Irene Villa, una víctima del terrorismo de ETA (ver Zapata, 2019). Estos tuits pasaron desapercibidos hasta que el concejal de Ahora Madrid adquirió una posición de preeminencia política y, por lo tanto, cambió la percepción que diferentes actores políticos tenían de él. ${ }^{8}$

Después de ser nombrado concejal de Cultura por Ahora Madrid, estos tuits llegaron a representantes políticos del Partido Popular y al equipo dirigido por la expresidenta Esperanza Aguirre, afectados por los escándalos políticos de la Comunidad de Madrid, quienes les dieron difusión en un nuevo contexto. El resultado: la polémica circuló rápidamente en grupos de WhatsApp y en tags contrarios al nuevo gobierno municipal como \#nopodeis.

8. Entre las implicaciones políticas más importantes del $15 \mathrm{M}$, estuvo la aparición de los denominados «ayuntamientos del cambio», gobernados por movimientos municipalistas y partidos políticos progresistas como Podemos. En el caso de Madrid, esta alianza de partidos y movimientos cívicos dio lugar a la formación Ahora Madrid, que logró la alcaldía de la ciudad en el año 2015. Uno de los protagonistas de la candidatura fue el escritor Guillermo Zapata, curtido en los movimientos del 15M y miembro de Indymedia Madrid. Cuando Ahora Madrid ganó las elecciones municipales, Zapata fue nombrado director del área de Cultura. 
En el ámbito de la prensa generalista, $A B C^{9}$ y $E l M u n d o^{10}$ fueron los primeros en construir al folk devil al resaltar las ideas antisemitas de Guillermo Zapata. Ambos periódicos son muy críticos con los tuits de Zapata e inician la campaña de desprestigio. Pedro J. Ramírez, director de El Español, pide directamente la dimisión de Zapata por sus comentarios ofensivos con las víctimas. En un tuit asegura que «en ningún país democrático ocuparía un cargo público alguien que fue capaz de escribir un tuit como el de Zapata» (13/6/2015). ${ }^{11}$

El posicionamiento de El País es interesante ya que en un principio se muestra un poco dubitativo, pero después se posiciona claramente en contra de Zapata ${ }^{12}$ y escribe un duro editorial contra el concejal en el que pide su dimisión (16/6/2015). ${ }^{13}$ En este sentido, los bloques ideológicos no están claramente perfilados. La polémica llegará a internacionalizarse y aparecen noticias relacionadas con el caso en Jerusalem Post ${ }^{14}$ y The New York Times. ${ }^{15}$

Una vez los medios han construido el caso, los actores políticos intervienen. La popular Esperanza Aguirre pide inmediatamente su dimisión. El Partido Socialista, que apoya la coalición de gobierno de Ahora Madrid, también pide la dimisión de Zapata a través de su candidato Antonio Miguel Carmona. ${ }^{16} \mathrm{Se}$ extiende el tag \#zapatadimision, que se hace trending topic (tendencia) nacional. Al mismo tiempo, se crea otro tag de apoyo a Zapata, \#esteeszapata, en el que participan diferentes colectivos de activistas, gentes del mundo de la cultura y personas anónimas, pero donde no participan figuras políticas relevantes de Ahora Madrid.

9. «Los tuits antisemitas del nuevo concejal de Cultura del Ayuntamiento de Madrid», publicado en $A B C(14 / 06 / 2015)$. Disponible en línea en <https://www.abc.es/madrid/20150613/ abci-guillermo-zapata-tuits-antisemitas-201506131824.html>, última visita 28/10/2019.

10. "Un comentario contra los judíos de Guillermo Zapata desata la polémica en Twitter», publicado en El Mundo (13/06/2015). Disponible en línea en <https://www.elmundo.es/ madrid/2015/06/13/557c57b3ca4741274e8b457a.html>, última visita 28/10/2019.

11. Sánchez, J. L., "Guillermo Zapata: historia de una polémica», publicado en eldiario.es (20/06/2015). Disponible en línea en <https://www.eldiario.es/juanlusanchez/sale-crecepolemica-Guillermo-Zapata_6_400419966.html\#!kalooga-24246/\%22Guillermo\%20 Zapata\%22>, última visita 28/10/2019.

12. Olaya, V., "Un edil de Ahora Madrid se burla en Twitter de los judíos y de Irene Villa», publicado en El Pais (14/06/2015). Disponible en línea en <https:/elpais.com/ ccaa/2015/06/13/madrid/1434219265_951793.html>, última visita 28/10/2019.

13. Editorial «Bienvenidos al poder. El caso Zapata muestra la fragilidad de las nuevas fuerzas emergentes», publicado en El País (16/06/2015). Disponible en línea en <https://elpais. com/elpais/2015/06/15/opinion/1434390601_883359.html>, última visita 28/10/2019.

14. Weinthal, B., "Spanish city councilman applauds burning of jews», publicado en The Jerusalem Times (14/06/2015). Disponible en línea en <https://www.jpost.com/Diaspora/ Spanish-city-councilman-applauds-burning-of-Jews-405942>, última visita 28/10/2019.

15. Minder, R., "Spanish oficial apologizes over Twitter joke about Holocaust», publicado en The New York Times (14/06/2015). Disponible en línea en <https://www.nytimes. $\mathrm{com} / 2015 / 06 / 15 /$ world/europe/spanish-official-apologizes-over-twitter-joke-about-holocaust.html>, última visita 28/10/2019.

16. «PP y PSOE piden la dimisión de un concejal de Ahora Madrid por bromear sobre el Holocausto en unos tuits de 2011", publicado en eldiario.es (14/06/2015). Disponible en línea en <https://www.eldiario.es/politica/Esperanza-Aguirre-Ahora-Madrid-Holocausto_0_398610264.html>, última visita 28/10/2019. 
Gráfico 1. Frecuencia de búsqueda de Guillermo Zapata, año 2015.

guillermo zapata

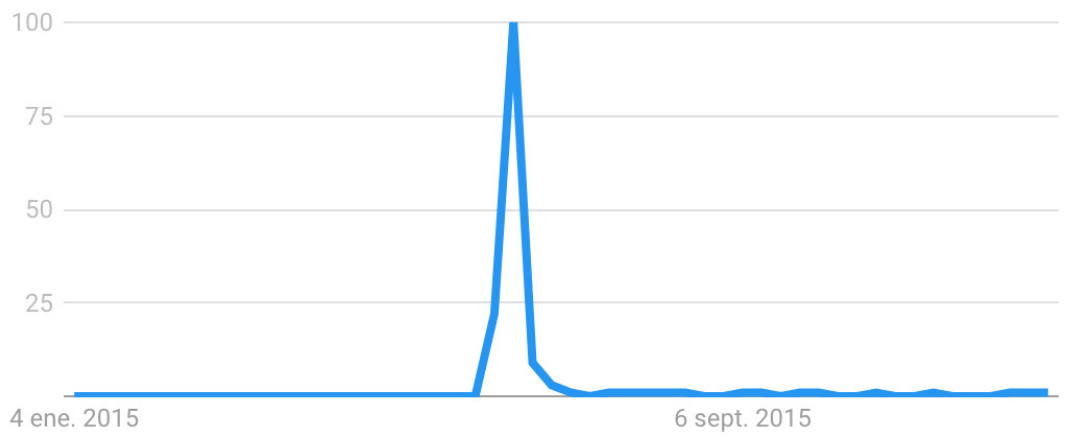

Fuente: Google Trends.

De forma general, los miembros de Ahora Madrid no salen públicamente en defensa de Zapata. Finalmente, la alcaldesa Manuela Carmena aparece en el programa de televisión El objetivo, conducido por Ana Pastor, y la política madrileña sugiere por primera vez que Zapata dimitirá de su cargo (14/6/2015). ${ }^{17}$ Más tarde, Zapata es entrevistado en El intermedio, donde trata de explicar el sentido de los tuits publicados años atrás y contextualizarlos en el marco de humor negro (16/6/2015).$^{18} \mathrm{La}$ intensidad y la brevedad de la exposición pública de Zapata se muestra en el gráfico 1, que contabiliza las búsquedas del caso en Google.

A partir de este momento, el pánico político-moral de Zapata se disipa rápidamente y solo reverbera en el juicio que le hace la Audiencia Nacional por enaltecimiento del terrorismo. Aunque el juez Santiago Pedraz rechaza hasta tres veces llevar a trámite la acusación contra Zapata, finalmente es juzgado y declarado inocente.

El mensaje que hay detrás del pánico moral que se genera con Zapata es que «hay que hacer algo al respecto» (Cohen, 1972). Es decir, hay que tomar medidas ejemplarizantes contra individuos que muestran unos posicionamien-

17. "Manuela Carmena: "No descarto cesar a Guillermo Zapata"», publicado en La Sexta (14/06/2015). Disponible en línea en <https://www.lasexta.com/programas/el-objetivo/ noticias/manuela-carmena-descarto-cesar-guillermo-zapata_201506145724d25d4beb28d 44600de56.html>, última visita 28/10/2019.

18. Palmero, M., "El intermedio - Wyoming se dispara con la entrevista a Guillermo Zapata», publicado en El Confidencial (16/6/2015). Disponible en línea en <https://www.elconfidencial.com/television/audiencias/2015-06-17/el-intermedio-wyoming-se-dispara-con-laentrevista-a-guillermo-zapata_889831/>, última visita 28/10/2019. 
tos morales inaceptables. Pero en este caso también sugiere un subtexto que llama a actuar contra individuos que no pertenecen al campo político, porque no tienen las cualidades exigibles ni la altura moral y, por tanto, no tienen la legitimidad para convertirse en actores políticos convencionales.

El caso de Zapata sigue los canales clásicos del escándalo político, aunque el personaje es construido también de acuerdo a los parámetros del pánico moral. La interpretación estricta de la ley permitió la judicialización de unos comentarios personales que habían pasado desapercibidos en el ámbito de la esfera pública cuando fueron originalmente publicados. Si los escándalos políticos clásicos afectan a actores establecidos del campo político y forman parte de las batallas reputacionales para establecerse en este ámbito, los pánicos morales afectan sobre todo a actores que no forman parte del campo político pero que tienen cierta influencia social. Este es el caso de Zapata en 2015. Aún no es un actor plenamente establecido en el campo político madrileño, más bien es un aspirante bien situado que pretende posicionarse de la mano de Ahora Madrid.

\subsubsection{La construcción del «demonio popular»: el caso de Cassandra}

La construcción de Cassandra Vera como enemigo público es efecto directo de la LOPSC. Tras la aprobación de la ley, la Guardia Civil puso en marcha una operación (la Operación Araña) para combatir el enaltecimiento del terrorismo en las redes sociales que supuso la identificación y la acusación de numerosos internautas que expresan sus opiniones en las redes sociales, sobre todo en Facebook y Twitter.

A diferencia de Zapata, estos internautas suelen ser personas desconocidas (hay excepciones, como la de César Strawberry, cantante del grupo de rap Def con Dos) que se convierten en personajes públicos a partir de la denuncia de la Guardia Civil y adquieren características básicas de los demonios populares. El de Cassandra, una tuiteta hasta entonces desconocida, es un caso paradigmático y con gran repercusión mediática.

Entre los años 2013 y 2016, Cassandra escribió varios tuits humorísticos que hacían referencia al atentado contra el político franquista Luis Carrero Blanco en 1973. Cuando cumplió 18 años, Cassandra fue denunciada por la Guardia Civil y puesta a disposición de la Audiencia Nacional por humillación a las víctimas del terrorismo. En contraposición al caso de Zapata, donde los bloques ideológicos no están claramente perfilados y un referente de la izquierda como El País se sitúa entre los acusadores del concejal, en el caso de Cassandra la separación ideológica en la interpretación de los hechos es ya muy nítida.

Los medios conservadores inician la campaña de construcción del demonio popular a partir de la acusación. Casualmente, en Cassandra se conjugan diferentes elementos que la hacen susceptible para ser atacada por estos medios: representa muchos valores denostados por este ámbito, algunos de los aspectos más sensibles del enfrentamiento cultural entre posiciones progresistas y conservadoras. Por un lado, sus tuits humorísticos reflejan una concepción 
progresista de la memoria histórica, muy crítica con el franquismo. Por el otro, se trata de una persona transgénero, por lo que su identidad sexual también cuestiona las concepciones tradicionales defendidas por la Iglesia católica y otras instituciones conservadoras.

En este ámbito, $A B C^{19}$ y El Español ${ }^{20}$ se posicionan a favor de la acusación e impulsan la construcción del pánico moral. Ambos diarios publican artículos donde se censuran los tuits de la autora, que consideran representativos de una personalidad violenta y peligrosa. De hecho, ambos periódicos hacen referencia a la intención de Cassandra de convertirse en profesora de Historia en Educación Secundaria, y problematizan sobre las condiciones de acceso a la profesión docente y el peligro de que determinados perfiles ultras acaben empañando ideológicamente la mente de los jóvenes. ${ }^{21}$

Una de las campañas más duras la realizó $O K$ Diario, que desveló muchos tuits ofensivos de Cassandra, y construyó su perfil de enemigo público. Además, su director, Eduardo Inda, apareció en espacios televisivos de debate, como La Sexta noche, reforzando la acusación. ${ }^{22}$ El programa El cascabel realizó todo un seguimiento del caso presentado los diferentes tuits escritos por Cassandra y denunciando el desprecio de su autora por las víctimas de terrorismo (30/3/2017). ${ }^{23}$ Por su parte, El Mundo muestra una aproximación más diversa, con variedad ideológica en sus colaboradores: mientras que algunos la tildan de «hater común ${ }^{24}$ (es decir, una small villain) (31/3/2017), otros consideran que todo el proceso es un esperpento de «Valle-Inclán en la era de Google» $(1 / 4 / 2017){ }^{25}$

19. Cervilla, P., «Sentencia ejemplar contra la tuitera Casandra, ¡ya era hora!», publicado en $A B C$ (31/03/2017). Disponible en línea en <https://abcblogs.abc.es/pido-la-palabra/sociedad/ sentencia-ejemplar-contra-la-tuitera-casandra-ya-era-hora.html>, última visita 28/10/2019.

20. Peral, M., "Cassandra, condenada a un año de prisión por sus tuits sobre Carrero Blanco», publicado en El Español (29/03/2017). Disponible en línea en <https:/www.elespanol.com/ espana/tribunales/20170329/204479880_0.html>, última visita 28/10/2019.

21. Uriarte, E., "Cassandra, una ultra muy crecida", publicado en $A B C(31 / 3 / 2017)$. Disponible en línea en <https://abcblogs.abc.es/edurne-uriarte/public/post/cassandra-una-ultra-muycrecida-17112.asp/>, última visita 28/10/2019.

22. "La tuitera a la que Iglesias apoya también pide asesinar a Sánchez Dragó, Sostres y Merkel», publicado en OK Diario (30/03/2017). Disponible en línea en <https://okdiario.com/investigacion/tuitera-cassandra-vera-pedia-asesinar-sanchez-drago-sostres-merkel-871146>, última visita 28/10/2019. Ver también el duro artículo de opinión de Eduardo Inda donde construye el perfil de la «malvada mediática». Inda, E., «Yo nunca diré "me molesta que no peguen un tiro a Cassandra"», publicado en OK Diario (09/04/2017). Disponible en línea en <https://okdiario.com/opinion/nunca-dire-molesta-no-peguen-tiro-cassandra-900116>, última visita 28/10/2019.

23. «El caso de la tuitera Cassandra», publicado por 13TV (30-03-2017). Disponible en línea en <https://www.youtube.com/watch?v=UcCc_iqk7fE>, última visita 28/10/2019.

24. Bustos, J., "Condenada Cassandra», publicado en El Mundo (31/03/2017). Disponible en línea en <https://www.elmundo.es/opinion/2017/03/31/58dd55aa22601daa308b460c. html>, última visita 28/10/2019.

25. Méndez, L., "Cassandra o el esperpento virtual», publicado en El Mundo (01/04/2017). Disponible en línea en <https://www.elmundo.es/opinion/2017/04/01/58de9324268e3e d8148b45df.html>, última vista 28/10/2019. 
Frente a la construcción conservadora del demonio popular, la prensa progresista defiende la libertad de expresión de la autora y denuncia la campaña de acoso contra ella. El País se posiciona claramente en favor de Cassandra y de la libertad de expresión. De hecho, en sus páginas se refiere a una carta publicada por la nieta de Carrero Blanco en que exculpa a Cassandra y afirma que es un "disparate» pedir penas de cárcel por la publicación de unos tuits sobre su abuelo $(19 / 1 / 2017) .^{26}$

Uno de los periodistas más respetados, Iñaki Gabilondo, dedica un videoblog al caso de Cassandra y denuncia la "paranoia policial» en la que se ha instalado la sociedad española (3/4/2017). ${ }^{27}$ Asegura que casos como el de Cassandra muestran las dificultades de entender la libertad de expresión en sociedades complejas. Sin embargo, las reacciones más contundentes llegan desde eldiario.es. Diversos comentaristas critican duramente la acusación y la sentencia contra Cassandra. ${ }^{28}$

$\mathrm{El}$ ataque reputacional que supone el pánico moral de Cassandra tiene sus efectos positivos en dicho periódico porque Cassandra se convierte a partir de 2018 en una articulista habitual del diario. El pánico moral le otorga la reputación para ser un referente del nuevo pensamiento progresista. Como consecuencia, son diversos los sectores de las redes sociales que también se movilizaron a favor de Cassandra con el tag \#yosoycassandra. Al igual que en el caso de Zapata, la exposición pública de Cassandra, reflejada en las búsquedas por internet, es muy breve pero intensa (ver gráfico 2).

La polémica de Cassandra muestra los elementos básicos del pánico moral elaborados por Cohen y Hall. Sin embargo, la efectividad de la polémica no es tan amplia como suponen estos autores (recordemos que para Hall estaban incluso vinculados con un proceso de construcción de hegemonía política). La demonización de Cassandra se realiza desde diferentes medios de comunicación y desde instancias judiciales como la Audiencia Nacional, pero la resistencia a este proceso de demonización es también fuerte e incluye sectores diversos de la sociedad. En este

26. Junquera, N., «La nieta de Carrero Blanco ve "un disparate” pedir cárcel por unos tuits sobre su abuelo", publicado en El País (19/01/2017). Disponible en línea en <https://elpais.com/ politica/2017/01/18/actualidad/1484771677_648133.html>, última vista 28/10/2019.

27. Gabilondo, I., «Los tweets», publicado en El País (03/04/2017). Disponible en línea en <https://cadenaser.com/programa/2017/04/03/hoy_por_hoy/1491203808_000671.html>, última visita 28/10/2019.

28. La publicación digital eldiario.es dedicó mucho espacio al caso de Cassandra y trató de desmontar la concepción de demonio popular construido por la prensa conservadora. Entre otros, pueden consultarse los siguientes artículos: Toledano, R., «La estúpida y cruel existencia española", publicado en eldiario.es (02/04/2017), disponible en línea en <https://www. eldiario.es/zonacritica/estupida-cruel-existencia-espanola_6_628947112.html>, última visita 28/10/2019; Elordi, C., "Habría que haber hecho mucho más por Cassandra», publicado en eldiario.es (31/03/2017), disponible en línea en <https://www.eldiario.es/zonacritica/hechoCassandra_6_628247211.html>, última visita 28/10/2019; Gallego, J., "Carrero Blanco que estás en los cielos», publicado en eldiario.es (30/03/2017), disponible en línea en <https:// www.eldiario.es/carnecruda/lo-llevamos-crudo/Carrero-Blanco-cielos_6_627897205.html>, última vista 28/10/2019. 
Gráfico 2. Frecuencia de búsqueda de Cassandra Vera, año 2017

Cassandra Vera

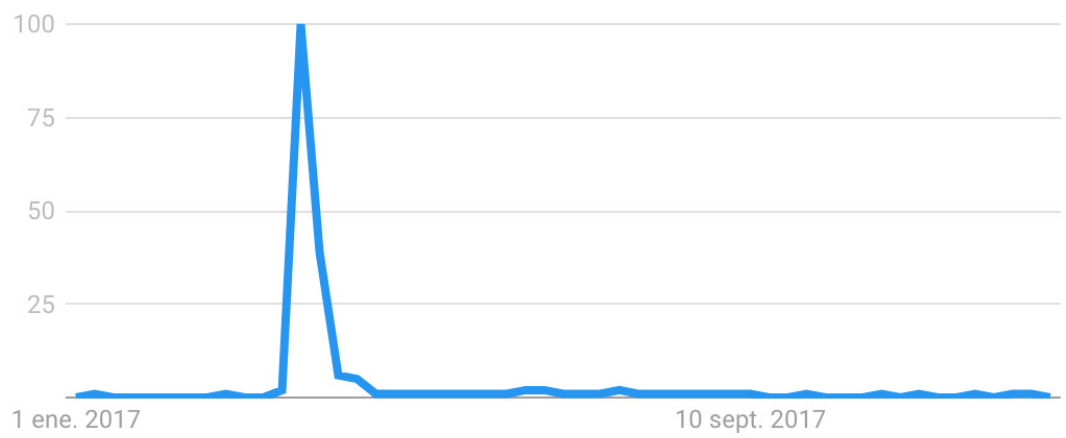

Fuente: Google Trends.

caso, parece que la polémica sirve, sobre todo, para aglutinar a distintos actores del ámbito progresista que reaccionan en medios y redes a los cambios sociales anunciados por la crisis de la cultura de la transición y la aparición de nuevas ideologías y sensibilidades sociales. A ese respecto, no logra articular un consenso hegemónico conservador más amplio.

2.2.3. La emergencia de los nuevos mods y rockers: Valtònyc y los raperos El caso de Valtònyc y los demás raperos condenados guarda cierto paralelismo con la demonización de mods y rockers en la Inglaterra de los años sesenta. Al igual que entonces, se trata de un colectivo con estética propia, producto de la subcultura y con una identidad fácil de representar, que puede mostrarse como desviación de la cultura dominante.

Sin embargo, ahora no se trata solo de regular comportamientos, sino también creaciones artísticas. El contenido político de las canciones de los raperos es visto como una amenaza por ciertos sectores conservadores, mientras que para las fuerzas progresistas forma parte de la libertad de expresión. El resultado es un reagrupamiento ideológico de distintos actores en la esfera pública.

El especial impacto de Valtònyc sobre el resto de raperos se debe a que es el primer músico con ingreso obligatorio en prisión tras la aprobación del nuevo marco legal. ${ }^{29}$ La confirmación de la sentencia por el Tribunal Supremo ${ }^{30}$

29. Aunque antes hubo otros condenados, como el del mencionado vocalista de Def con Dos, César Strawberry, el de Pablo Hasél o el de los miembros del grupo La Insurgencia, todos ellos tuvieron penas inferiores a dos años y, al no tener antecedentes, evitaron la cárcel.

30. El Alto Tribunal fija la condena en tres años y medio por delitos de enaltecimiento del terrorismo, calumnias e injurias a la corona y amenazas no condicionadas cometidos con sus canciones. 
Gráfico 3. Frecuencia de búsqueda de Valtònyc, año 2018

Valtonyc

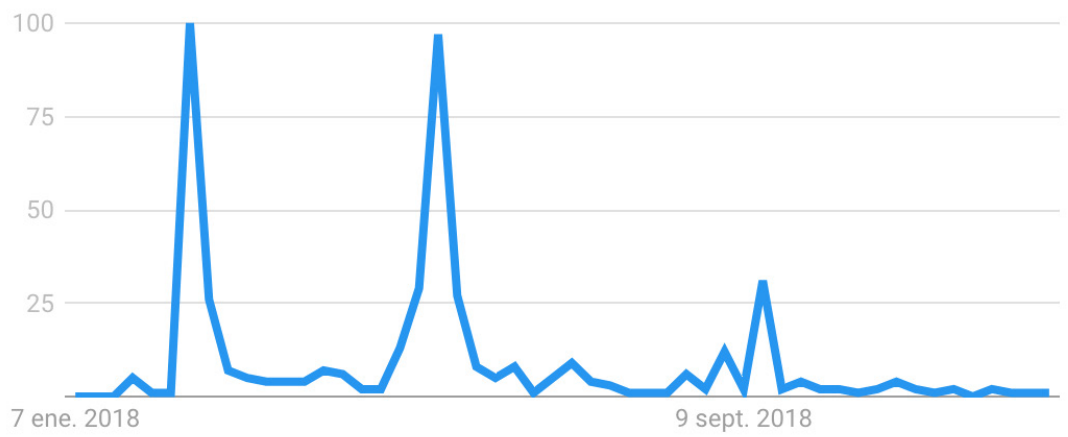

Fuente: Google Trends.

dispara la atención y, como sucede con Zapata y Cassandra, el número de búsquedas por internet aumenta exponencialmente durante unos días. Aunque, a diferencia de estos casos, la presencia pública de Valtònyc se mantiene en el tiempo debido a su creciente vinculación con el independentismo catalán (ver gráfico 3)..$^{31}$

La sentencia activó la discusión securitaria en los medios conservadores. En $A B C$, el periodista y locutor Carlos Herrera refuerza el encuadre punitivo al poner el foco en la comisión de un delito por encima de la expresión artística: «No es cosa de censura ni de libertad de creación. Son delitos consecutivos que, ya lo siento hijo, te van a enviar a la cárcel». ${ }^{32}$ Otro de los referentes del espectro mediático de la derecha, Federico Jiménez Losantos, se expresa en la misma línea y lamenta que la condena no sea incluso mayor calificando la sentencia de «sadismo tolerado». El periodista va más allá y relaciona los hechos con las víctimas del terrorismo, un paso importante en la configuración del pánico moral, al identificar no solo al demonio popular (Valtònyc), sino también a unos afectados (víctimas del terrorismo): «Lo justo serían tres años en el zulo de Ortega Lara, que es de quien se burla. Hemos perdido de

31. El primero de los picos sucede meses después de la sentencia, en mayo de 2018, cuando para evitar su ingreso en prisión Valtònyc huye a Bélgica (donde se encuentra también huido de la justicia española el expresidente de la Generalitat Carles Puigdemont, con quien va a compartir abogado). El segundo sucede en septiembre, a la espera del anuncio sobre si la justicia belga extradita al rapero a España.

32. "Ya lo siento hijo», publicado en $A B C$ (23/02/2018). Disponible en línea en <https:// www.abc.es/opinion/abci-siento-hijo-201802230733_noticia.html>, última visita 28/10/2019. 
vista que la libertad de expresión es la libertad del verdugo de escupir sobre las víctimas, y no». ${ }^{33}$

Otra cuestión interesante es cómo, al igual que sucedió con Cassandra, se trascendió el hecho concreto (un tuit, una canción) y la discusión se amplió a una disputa política de mayor alcance. Valtònyc es presentado como síntoma de lo que se denomina radicalismo de izquierda post-15M y del independentismo catalán anti-sistema (Podemos y la CUP), y su figura se asocia a personajes políticos emergentes, como Pablo Iglesias o Ada Colau. En Libertad Digital, Eduardo Goligorsky establece una relación directa y señala al rapero y a la alcaldesa de Barcelona como representantes de un «autoritarismo intolerante». 34

Frente al encuadre mediático conservador, la prensa progresista presenta los hechos como un retroceso generalizado de la libertad de expresión a consecuencia de las reformas legales. En especial, el periódico eldiario.es se muestra muy activo. En su portal web, el locutor Javier Gallego relaciona la sentencia con la existencia de un Estado autoritario que perpetúa el sistema de privilegios. El periodista argumenta que la libertad de expresión se ve limitada en España cuando se refiere a alguno de sus pilares simbólicos: el rey, dios o el Ibex-35. ${ }^{35}$ En el mismo medio, Guillermo Zapata (nuestro primer demonio popular) también apunta hacia estos pilares y la "crisis de consensos sociales" en torno a ellos, lo que estaría provocando fuertes tensiones ante los nuevos horizontes abiertos: «Una suerte de pánico ante la multiplicidad de posibles salidas a esta situación de falta de consensos colectivos fuertes». ${ }^{36}$

La discusión sobre el caso Valtònyc se conectó con un debate más amplio sobre securitización y libertad de expresión en España debido a la coincidencia en el tiempo de otros dos acontecimientos relacionados. El primero es el secuestro del libro Fariña, del periodista Nacho Carretero, cuya temática está relacionada con el narcotráfico en Galicia y sus conexiones políticas. ${ }^{37}$ El segundo, la decisión de Ifema de retirar una instalación de la

33. Jiménez Losantos, «El periodismo es una enfermedad de izquierdas», publicado en eldiario.es (25/02/2018). Disponible en línea en <https://www.eldiario.es/cultura/Jimenez-Losantosperiodismo-enfermedad-izquierdas_0_744025628.html>, última visita 28/10/2019.

34. «Intolerantes con los intolerantes», publicado en Libertad Digital (09/03/2018). Disponible en línea en <https:/www.libertaddigital.com/opinion/eduardo-goligorsky/intolerantes-conlos-intolerantes-84594/>, última visita 28/10/2019.

35. "La libertad de expresión es más sagrada que dios, el rey y el Ibex 35», publicado en eldiario.es (21/02/2018). Disponible en línea en <https://www.eldiario.es/carnecruda/ lo-llevamos-crudo/libertad-expresion-sagrada-dios-Ibex_6_742685753.html>, última visita 28/10/2019.

36. "Una rabia repentina», publicado en eldiario.es (28/02/2018). Disponible en línea en <https://www.eldiario.es/tribunaabierta/libertad-expresion-pais-estrecho_6_745135509. html>, última visita 28/10/2019.

37. La decisión el Juzgado de Instrucción no 7 de Collado Villalba llegó después de que el exalcalde de El Grove (Pontevedra) Alfredo Bea Gondar denunciase por injurias y calumnias al autor y a la editorial. Finalmente, la Audiencia Provincial de Madrid revocó el secuestro y el 22 de junio del mismo año el libro volvió a venderse. 
Feria Internacional de Arte Contemporáneo de Madrid (Arco) dedicada a presos políticos que incluía a los independentistas catalanes Oriol Junqueras y Jordi Sànchez.

Estos hechos provocaron que durante esos días diversos medios del ámbito progresista pusieran el foco en el debate y profundizaran sobre sus consecuencias. En un editorial del diario El Pais se alerta directamente sobre los efectos de las reformas legales y la inseguridad jurídica que provocan (22/02/2018). ${ }^{38}$ El mismo periódico, días después, dedica otro editorial a los efectos sociales de la discusión abierta con la LOPSC. En el texto muestra su preocupación sobre el cambio de valores que la ley puede suponer en la cultura cívica española, que, caracterizada por ser tolerante en cuestiones valores, parece cada vez más «mojigata e intolerante» (26/02/2018)..$^{39} \mathrm{El}$ debate traspasa fronteras, y medios como la $\mathrm{BBC}^{40}$ y The New York Times ${ }^{41}$ publican sendos reportajes sobre el retroceso de la libertad de expresión en España.

Especialmente interesante es la discusión que se genera en la prensa catalana (La Vanguardia y El Periódico), donde los hechos se vinculan al debate de fondo sobre el modelo territorial y las relaciones entre el Estado y Cataluña. En La Vanguardia, el periodista Jordi Amat muestra su preocupación ante lo que considera una degradación de la calidad de la democracia española (22/02/2018) ${ }^{42}$ En el mismo medio, Màrius Serra va más allá y relaciona las decisiones judiciales con una reacción contra la disidencia política: «La disidencia nacional resulta insoportable. El miedo se está convirtiendo en pánico (...) esta reiterada represión preventiva es hija de un miedo muy espeso" (24/02/2018). ${ }^{43}$ En un sentido parecido, el presentador Jordi Évole escribe en El Periódico que estos acontecimientos tienen el objetivo disciplinar ideológicamente: "Querrían que la mente

38. «Libertad de expresión», publicado en El Pais (22/02/2018). Disponible en línea en <https://elpais.com/elpais/2018/02/21/opinion/1519238794_200996.html>, última visita 28/10/2019.

39. «Sociedad mojigata», publicado en El País (22/02/2018). Disponible en línea en <https:// elpais.com/elpais/2018/02/23/opinion/1519406856_609008.html>, última visita 28/10/2019.

40. «The Spanish rappers getting 'terror' sentences for songs», publicado en BBC (17/03/2018). Disponible en línea en <https:/www.bbc.com/news/world-europe-43407694?intlink_ from_url=<http://www.bbc.com/news/topics/c302m85qenvt/spain\&link_location=livereporting-story>, última visita 28/10/2019.

41. «Spanish Artwork Denounced Political 'Persecution'. It Was Ordered Removed», publicado en The New York Times (21/02/2018). Disponible en línea en <https://www. nytimes.com/2018/02/21/world/europe/spain-art-censorship-catalonia.html última visita 28/10/2019>.

42. "24 horas de degradación», publicado en La Vanguardia (22/02/2018). Disponible en línea en <http://hemeroteca.lavanguardia.com/preview/2018/02/21/pagina-36/162868453/pdf. html?search=Valtonyc $>$, última visita 28/10/2019.

43. «La España monolingüe», publicado en La Vanguardia (24/02/2018). Disponible en línea en <http://hemeroteca.lavanguardia.com/preview/2018/02/24/pagina-39/163318742/pdf. html?search=Valtonyc $>$, última visita 28/10/2019. 
de muchos españoles disminuyese. Que volviésemos a tiempos pretéritos» $(25 / 02 / 2018) .44$

El debate también cobró vida en las redes sociales, en especial en Twitter. El hashtag \#RapearNoesDelito se conviritió en trending topic en defensa de los raperos condenados. Diversas personalidades tuitearon en apoyo a Valtònyc y los demás artistas afectados, entre ellos el líder de Podemos, Pablo Iglesias, y la alcaldesa de Barcelona, Ada Colau, quienes habían sido blanco de la prensa conservadora.

$\mathrm{Al}$ igual que sucedió con Zapata y Cassandra, el pánico se orquestó desde la esfera pública, pero pronto comenzó a tener implicaciones en la arena política. La diferencia es que ahora el objetivo del pánico ya no es el humor negro, sino la creación artística, y los demonios populares, personajes con cierto reconocimiento en el ámbito de subculturas (rap). El contenido de sus canciones se convierte en tema de disputa ideológica en términos de libertad de expresión / seguridad ciudadana. Otro de los rasgos más llamativos que introduce el caso de Valtònyc en la evolución de estos pánicos político-morales es su disponibilidad para una reactivación posterior, incluso bastante después de que haya desaparecido de escena, según las oportunidades de la coyuntura política. De esta forma, la figura de "demonio popular» puede ser retomada en nuevos contextos para atacar a adversarios o denigrar propuestas políticas.

\section{Conclusiones}

Los pánicos político-morales son fenómenos habituales en la esfera pública contemporánea. Tienen características distintivas respecto a los escándalos políticos y están asociados a proyectos hegemónicos más amplios, impulsados por actores sociales diversos (periodistas, opinadores, expertos, políticos, etcétera). Por tanto, conviene no relegarlos como fenómenos sociopolíticos secundarios e intrascendentes. En este trabajo, hemos analizado tres casos relevantes que muestran la evolución de los pánicos político-morales en la esfera pública española reciente: los casos de Guillermo Zapata, Cassandra y Valtònyc.

Estos casos muestran cómo determinadas bromas (o comentarios críticos) que hasta ese momento eran muestras de humor negro o simple mal gusto, caracterizadas por la aceptación social y el desinterés público, de repente alcanzaron el centro de atención y se convirtieron en objeto de denuncia. Es evidente que en estos casos lo importante no son las bromas en sí mismas, sino las líneas de fractura ideológica que desvelan las reacciones de ofensa e indignación. Unas bromas (o unos comentarios críticos) que eran aceptables y no superaban nunca los círculos íntimos de repente se convierten en asuntos públicos y en problemas de seguridad, sobre los que hay que realizar denuncias públicas, imponer ceremonias de disculpa e iniciar procesos judiciales. Este

44. «Demasiada censura para tan pocos días», publicado en El Periódico (25/02/2018). Disponible en línea en <https:/www.elperiodico.com/es/opinion/20180225/demasiada-censurapara-tan-pocos-dias-jordi-evole-6649400>, última visita 28/10/2019. 
castigo social sobre la conducta desviada (o más bien la opinión desviada) se realiza sobre personas individuales, generalmente conocidas (como Guillermo Zapata), pero también anónimas (como Cassandra). Los medios de comunicación de masas y las redes sociales se convierten en el teatro donde se escenifican estos procesos morales y judiciales.

Aunque en el caso español pueden encontrarse algunos antecedentes, como los procesos judiciales abiertos al músico Javier Krahe por un delito de ofensa a los sentimientos religiosos por un vídeo donde "cocinaba» un Cristo, o al actor Pepe Rubianes por ultraje a España tras unas polémicas declaraciones en televisión (en ambos casos salieron absueltos), lo novedoso de los episodios analizados es el contexto de securitización creciente en el que se encuadran, debido a la reforma del Código Penal y la entrada en vigor de la LOPSC. Por supuesto, los casos de Zapata, Cassandra y Valtònyc no son los únicos existentes en los últimos años, pero ilustran muy bien la construcción de pánicos políticomorales después de la crisis del campo político español generada por el 15-M.

Tras estos casos, la proliferación de pánicos ha continuado y, posiblemente, alcanzó un punto álgido en noviembre de 2018 con la polémica del humorista Dani Mateo y su gag sobre la bandera española. En esta ocasión, se reproducen (y amplifican) muchas de las características de los pánicos político-morales que hemos visto hasta ahora: utilización humorística de un símbolo nacional, orquestación de una reacción mediática contra el humorista, consolidación de dos posicionamientos ideológicos que atacan y defienden respectivamente a Dani Mateo. Los críticos consideraron que la performance mediática de Mateo al sonarse la nariz con la bandera era inaceptable, porque era irrespetuosa con un símbolo fundamental de la nación española. Para los defensores, el humorista y el programa de televisión El intermedio (La Sexta) se habían limitado a realizar un gag humorístico apelando al mismo tiempo a la libertad de expresión. La polémica acarreó consecuencias importantes: El intermedio tuvo que disculparse públicamente, y el humorista perdió diversas campañas publicitarias y fue denunciado por un sindicato policial, acusado de ofensa y ultraje a símbolos españoles.

Casi en paralelo a la polémica de Dani Mateo, se produce otro fenómeno que implica cierta reconfiguración del funcionamiento clásico de los pánicos político-morales. Recordemos que en los estudios de Stanley Cohen y Stuart Hall las reacciones a los pánicos morales proceden siempre de los sectores conservadores de la sociedad. Estos escándalos, aunque sea de forma simbólica, cuestionan elementos centrales del statu quo y, por ello, provocan la reacción de aquellos que defienden el orden social y sienten aversión al cambio. Los casos que hemos presentado aquí también provocaron la reacción de los sectores conservadores de la sociedad, aquellos que defienden el orden constitucional español de 1978 y que, al mismo tiempo, exigen un cierto respeto por la sacralidad de los símbolos nacionales y patrióticos.

Sin embargo, durante 2018, puede observarse la aparición de nuevos pánicos político-morales (que siguen mostrando la estructura y la dinámica analizadas más arriba) procedentes de sectores progresistas de la sociedad. 
Son los colectivos progresistas, o aquellos que defienden los ideales ilustrados de la transformación social, los que empiezan campañas de denuncia contra determinadas formas de humor o de mal gusto que consideran inaceptables en la esfera pública. En este caso, los «objetos sagrados» defendidos no son los símbolos nacionales, sino la diferencia y la dignidad de las distintas definiciones identitarias (etnia, género, diversidad sexual). La polémica del humorista Rober Bodegas con sus chistes sobre el colectivo gitano es un ejemplo de la redefinición del pánico político-moral, y de la entrada en escena del «emprendedor moral» progresista e interseccional. No se trata de un fenómeno radicalmente nuevo, pero sí redefine los pánicos político-morales en la esfera pública posterior al 15M.

Del mismo modo que en los pánicos de origen conservador, detrás de los pánicos progresistas se esconde la articulación de un proyecto hegemónico para la sociedad. Las características y los tipos de escándalos que afloran en la esfera pública muestran las líneas maestras de este proyecto de reconstrucción social, basado en la reconfiguración de las identidades socialmente legítimas. Sin embargo, y de forma coincidente con los pánicos morales conservadores, se trata de un proyecto hegemónico de difícil culminación: es cierto que atrae múltiples adhesiones de los sectores más izquierdistas, pero también fomenta la reacción y la recomposición del frente conservador. En ambos casos, el conflicto no se limita a las opiniones vertidas en la esfera pública (a través de los mass media o las redes sociales), sino que se amplía a la interpretación de los contenidos de la cultura popular (sobre todo chistes de humoristas y letras de canciones).

En definitiva, estas tensiones nos presentan los pánicos político-morales como un mecanismo cada vez más frecuente de disputa política en la esfera pública. Surgen del disenso sobre cuestiones centrales de la cultura política y constituyen espacios discursivos en los que distintas visiones ideológicas entran en contienda para definir un problema político y legitimar así valores sociales y decisiones políticas. Este proceso es dinámico y los distintos actores en liza tienen la capacidad no solo de crear nuevos marcos de significados o de defenderse ante aquellos que les son desfavorables, sino también de reapropiárselos y reinterpretarlos. Como hemos visto con los «demonios populares» analizados, los tres protagonistas (y quienes les apoyaron) tuvieron la capacidad de intervenir y reforzar su propio campo ideológico: Zapata y Cassandra pasan a ser articulistas de referencia en la prensa progresista, y Valtònyc se convierte en un icono del independentismo catalán. Aunque los pánicos son efímeros, sus efectos políticos son duraderos.

Un último apunte: la revisión del presente trabajo se ha realizando en plena pandemia de la COVID-19, generadora de intensos pánicos mediáticos. Si los casos seleccionados se sitúan en el contexto securitario generado por la crisis del campo político a partir del año 2008 y la aparición del movimiento $15 \mathrm{M}$, posiblemente la pandemia de la COVID-19 impulsará un contexto sociopolítico diferente, caracterizado por la explosión de nuevas emergencias y ansiedades sociales. Dicha transformación podría redefinir, una vez más, los contornos de los fenómenos sociales que acaban adquiriendo la forma de pánicos morales. 


\section{Agradecimiento y financiación}

Este artículo es producto del Proyecto de $\mathrm{I}+\mathrm{D}$ «Discursos y representaciones sobre seguridad y su impacto en la cultura política en España» (CSO201786985-R) (2018-2020), financiado por el Ministerio de Economía, Ciencia y Competitividad de España (Mineco), dentro de Proyectos Excelencia y Proyectos Retos, Agencia Estatal de Investigación, Convocatorias 2017.

\section{Referencias bibliográficas}

Castells, Manuel (2012). Redes de indignación y esperanza. Madrid: Alianza Editorial. Castromil, Antón y Resina, Jorge (2013). «La prensa tradicional en la España del 15-M». En: Actores y demandas en España: análisis de un inicio de siglo convulso, 107-129. Los Libros de la Catarata.

Calle Collado, Ángel (2016). «Ciclos políticos y ciclos de movilización. Entre el 15M, Podemos y nuevos municipalismos». Historia Actual Online, 40 (2), 79-94.

Chavero, Paloma (2015). Prensa y política en tiempos de crisis: estudio de la legislatura 2008-2011. Madrid: Centro de Investigaciones Sociológicas.

Cohen, Stanley (2011) [1972]. Folk devils and moral panics: the creation of mods and rockers. Nueva York: Routledge.

Durán, Rafael (2018). «Enfoques mediáticos sobre libertad y seguridad. La ley española de Seguridad Ciudadana como estudio de caso». Política y Sociedad, 55 (1), 211-234. <https://doi.org/10.5209/POSO.54808>

Fernández de Monsteyrin, Laura (2018). «Stanley Cohen: demonios populares y pánicos morales». Encrucijadas, 16, 1-4.

Fernández-Savater, Amador (2012). «El 15-M y la crisis de la cultura consensual en España». Periférica, 13, 63-71. <https://doi.org/10.25267/periferica.2012.i13.05>

Garland, David (2008). «On the concept of moral panic». Crime, Media, Culture, 4 (1), 9-30. <https://doi.org/10.1177/1741659007087270>

Hall, Stuart et al. (1978). Policing the Crisis: Mugging, the State, and Law and Order. Londres: McMillan Press.

Hallin, Daniel y Mancini, Paolo (2011). Comparing media systems beyond the Western world. Cambridge: Cambridge University Press.

Jacobs, Ronald N. y Townsley, Eleanor (2011). The space of opinion. Media intellectuals and the public sphere. Oxford: Oxford University Press.

Jenkins, Philip (2009). «Failure To LaunchWhy Do Some Social Issues Fail to Detonate Moral Panics?». The British Journal of Criminology, 49 (1), 35-47. $<$ https://doi.org/10.1093/bjc/azn016>

Jewkes, Yvonne (2015). Media and crime. Thousand Oaks (CA): Sage.

KLocke, Brian V. y Muschert, Glenn W. (2010). «A hybrid model of Moral panic: synthesizing the theory and practice of moral panic research». Sociology Compass, 4/5, 295-309. <https://doi.org/10.1111/j.1751-9020.2010.00281.x>

LABRADOR, Germán (2014). «¿Lo llamaban democracia? La crítica estética de la política en la transición española y el imaginario de la historia en el 15-M». Kamchatka. Revista de Análisis Cultural (4), 11-61.

$<$ https://doi.org/10.7203/kam.4.4296> 
Lindgren, Simon (2013). «Pirate Panics». Information, Communication \& Society, $16,8,1.242-1.265$. <https://doi.org/10.1080/1369118x.2012.757632>

Markovits, Andrei y Silverstein, Mark (eds.) (1988). The politics of scandal: Power and process in liberal democracies. Nueva York: Holmes \& Meier.

Martínez, Guillem (2012). CT o la Cultura de la Transición. Critica a 35 años de cultura española. Barcelona: Debolsillo.

McRobbie, Angela y Thornton, Sarah (1995). «Rethinking moral panic for multi-mediated social worlds». British Journal of Sociology, 46 (4), 559-74. $<$ https://doi.org/10.2307/591571>

Morán Calvo-Sotelo, María Luz (2011). «La cultura política en España: interrogantes, debates y aportaciones». En: A cincuenta años de la cultura cívica: pensamientos y reflexiones en honor al profesor Sidney Verba. Instituto de Investigaciones Jurídicas, 101-122. México: UNAM.

Pecourt, Juan (2015). «La esfera pública digital y el activismo político». Política y Sociedad, 52 (1), 75-98. <https://doi.org/10.5209/rev_poso.2015.v1.n52.45423>

Picó, Josep y Pecourt, Juan (2013). Los intelectuales nunca mueren: una aproximación socio-histórica (1900-2000). Barcelona: Barcelona.

Resina, Jorge (2011). «Los lunes al sol: jóvenes, ciberpolítica y acción colectiva en la España del 15-M». Umbrales. Revista del Postgrado Multidisciplinario en Ciencias del Desarrollo, 22, 70-80.

Romanos, Eduardo (2017). "The strategic use of humor in the Spanish Indignados/15M Movement». En: Crisis and Social Mobilization in Contemporary Spain, 133-153. Routledge. <https://doi.org/10.4324/9781315574875-7>

Thompson, John B. (1995). The media and modernity. A social theory of the media. Cambridge: Polity.

- (2000). Political scandal. Power and visibility in the media age. Cambridge: Polity.

Toret, Javier (2013). «Tecnopolítica: la potencia de las multitudes conectadas. El sistema red 15M, un nuevo paradigma de la política distribuida». IN3 Working Paper Series.

<https://doi.org/10.7238/in3wps.v0i0.1878>

UnGar, Sheldon (2001). «Moral panic versus the risk society: the implications of the changing sites of social anxiety». British Journal of Sociology, 52 (2), 271-91. <https://doi.org/10.1080/00071310120044980>

Wright, Sarah (2015). «Moral panics as enacted melodramas». British Journal of Criminology, 55 (6), 1.245-1.262. <https://doi.org/10.1093/bjc/azv025>

Zapata, Guillermo (2019). Libertad de expresión, ansiedad tecnológica y crisis política. Madrid: Lengua de Trapo. 